\title{
The Reproducibility of Biometry and Keratometry Measurements
}

\author{
J. M. BUTCHER and C. O'BRIEN
}

Liverpool

\begin{abstract}
Summary
Axial length and corneal curvature are entered into formulae to calculate intraocular lens power for cataract surgery and the absolute measurement of fundus structures such as neuroretinal rim area in glaucoma. The reproducibility (coefficient of variation, $\mathrm{CV}$ ) of biometry and keratometry was investigated by taking five measurements of thirty phakic eyes. Although both techniques were found to be highly reproducible $(\mathrm{CV}<1 \%)$, keratometry was the more so. However, a clinically significant difference was noted between the first and the mean of five readings for both biometry $(0.15 \pm 0.05 \mathrm{~mm})$ and keratometry $(0.05 \pm 0.03)$. Taken together, these errors would result in a postoperative refractive error of $0.65 \mathrm{D}$ using the SRK formula. Measurement errors were just as likely to occur with short or long eyes. Similar results were found when the analysis was performed on three measurements of both axial length and corneal curvatures. We recommend taking the average of three biometry and keratometry readings to improve the reliability of the techniques, and to increase the accuracy of calculating intraocular lens power and fundus structure dimensions.
\end{abstract}

At present axial length and corneal curvature measurements are widely used in formulae for calculating the required power of an intraocular lens (IOL) implant. These measurements are also entered in Littmann's formula ${ }^{1}$ for the calculation of fundus structures such as optic disc and neuro-retinal rim area $\mathrm{a}^{2,3}$ and retinal nerve fibre layer thickness. ${ }^{4}$

Although biometry and keratometry are widely used, little is known of the reproducibility of ultrasonography for measuring axial length, or of keratometry for measuring corneal curvature. It is clear from the formulae that small errors in biometry and keratometry may lead to larger errors in the calculation of IOL power or fundus structures. It is essential, therefore, that the instruments and techniques used to measure axial length and corneal curvature are both accurate and reproducible. The aim of this study was to determine the reproducibility of A-scan biometry to measure axial length, and of keratometry to measure corneal curvature, and to test the accuracy of a single measurement of each parameter.

\section{Patients and Methods}

Thirty patients admitted for routine cataract extraction were recruited for the study and informed consent was obtained. For this study, measurements were made on the phakic fellow eye using a 3M Digiecho III A-scanner and a Haag-Streit Javal-Schiotz type keratometer. Normal conditions for single readings were simulated as far as possible by repositioning the patient's chin on the rest between keratometry readings, and by reapplying the ultrasound applanation probe 
Table I. Coefficient of variation and difference betwen first and mean value for 5 readings of 30 patients

\begin{tabular}{lcc}
\hline & $\begin{array}{c}\text { Coefficient of } \\
\text { variation } \\
\text { (mean } \pm S D, \%)\end{array}$ & $\begin{array}{c}\text { Difference } \\
\text { between } \\
\text { first and } \\
\text { mean value } \\
\text { (mean } \pm S D, m m)\end{array}$ \\
\hline $\begin{array}{l}\text { Axial length } \\
\text { Keratometry }\end{array}$ & $0.76 \pm 0.64$ & $0.15 \pm 0.05$ \\
K1 & $0.56 \pm 0.15$ & $0.05 \pm 0.03$ \\
K2 & $0.59 \pm 0.25$ & $0.05 \pm 0.03$ \\
\hline
\end{tabular}

between axial length measurements. Keratometry readings were made first, before application of topical anaesthetic drops for corneal anaesthesia. All measurements were made by one investigator (JMB) on a single apparatus to minimise interobserver error. ${ }^{5}$ The ultrasound oscilloscope was set on manual mode, and the trace frozen when sharp peaks, corresponding to lens capsule and retinal reflections, were obtained.

Five axial length $(\mathrm{AL})$ and five keratometry (K1 and K2) measurements were made for each eye. The coefficient of variation $(\mathrm{CV}$ : standard deviation/mean $\times 100 \%$ ), and the difference between the first reading and the mean value was calculated for both biometry and keratometry. The CV was used as an index of the reproducibility of the measurements on an individual eye. To give an indication of whether or not readings on larger eyes were less reproducible, the correlation coefficient $(r)$ between the mean and the standard deviation was calculated for both biometry and keratometry.

\section{Results}

The mean axial length of the thirty eyes was $23.21 \pm 2.00 \mathrm{~mm}$ (range $21.09-30.48 \mathrm{~mm}$ ) and the mean keratometry was $7.43 \pm 0.28 \mathrm{~mm}$ (range $6.76-8.03 \mathrm{~mm}$ ). The $\mathrm{CV}$ was $0.76 \pm 0.64 \%$ for biometry, and for keratometry $\quad 0.56 \pm 0.15 \% \quad$ (K1) and $0.59 \pm 0.25 \%$ (K2) (Table I). The difference between the mean and first reading was $0.15 \pm 0.5 \mathrm{~mm}$ for axial length, and $0.05 \pm 0.03 \mathrm{~mm}$ for both $\mathrm{K} 1$ and $\mathrm{K} 2$. In two eyes the difference between the first of five measurements of axial length and the mean was greater than $0.5 \mathrm{~mm}$. The difference between the first and mean keratometry read- ings was $0.1 \mathrm{~mm}$ in three eyes, but in no case was the difference greater. The correlation coefficient ( $r$ ) between the mean and the standard deviation of the mean for axial length was $r=0.02(p>0.1)$ and for keratometry was $\mathrm{r}=0.19(\mathrm{p}>0.1)$.

Similar calculations were also made for the first three of five measurements. Mean figures for three readings were $23.19 \pm 2.04 \mathrm{~mm}$ (axial length) and $7.43 \pm 0.29 \mathrm{~mm}$ (keratometry). The relevant CVs were $0.73 \pm 0.74 \%$ (axial length), $0.54 \pm 0.25 \% \quad$ (K1) and $0.56 \pm 0.32 \%(\mathrm{~K} 2)$. The differences between mean and first readings for three readings were $0.15 \pm 0.16 \mathrm{~mm}$ (axial length) and $0.03 \pm 0.02 \mathrm{~mm}(\mathrm{~K} 1$ and $\mathrm{K} 2)$.

\section{Discussion}

It is well established that preoperative biometry enables more accurate selection of IOL power for a desired postoperative refraction. ${ }^{6-11}$ However it has also been pointed out that in patients with mild to moderate preoperative refractive errors the use of a standard power IOL, or of one that has been calculated from preoperative refraction, will be satisfactory. ${ }^{12}$ When using biometry, small inaccuracies may lead to larger differences in postoperative refraction. In our study the average difference between first and mean axial length measurements was $0.15 \mathrm{~mm}$ for either three or five measurements. When using the SRK formula this will lead to a difference in postoperative refraction of $0.38 \mathrm{D}$. Similarly an average error in keratometry of $0.05 \mathrm{~mm}$ would give a $0.27 \mathrm{D}$ change. It is important therefore not to rely on a single measurement of biometry or keratometry as this may result in inaccurate postoperative refractions. The clinical importance of accurately calculating optic disc and other fundus dimensions, particularly neuroretinal rim area and retinal nerve fibre layer thickness in glaucoma patients, is that these structures may change over time during the course of the disease. Any inaccuracy in biometry or keratometry values entered in Littmann's formula ${ }^{1}$ may obscure or alter this change.

The reproducibility of five measurements of axial length and corneal curvature is given, in our study, by the coefficient of variation (CV) of $0.76 \%$ and $0.57 \%$ respectively. The 
CVs for three measurements were $0.73 \%$ and $0.55 \%$. This indicates that both techniques are highly reproducible. Hannah et al. ${ }^{13}$ found that measurements of central corneal curvature made with the keratometer were more reproducible than those made with the corneascope or corneal modelling system. They also pointed out that the keratometer was also cheaper, quicker and required less training than the other methods when used for these measurements. Longstaff also found variations in biometry; ${ }^{5}$ he found an average difference between observers on the same eye of $0.44 \mathrm{~mm}$ and $0.5 \mathrm{D}$ (approximately $0.1 \mathrm{~mm}$ ) for axial length and keratometry respectively. Sanders and $\mathrm{Kraff}^{14}$ took six to eight axial length measurements until consecutive readings differed by $0.1 \mathrm{~mm}$ or less. We suggest an average of three readings should be calculated; in our study the coefficient of variation of three measurements was no greater than that of five readings. It has previously been reported that the predictive accuracy of IOL power calculation is reduced in short $(<21 \mathrm{~mm})$ and long $(>25 \mathrm{~mm})$ eyes. ${ }^{15-18}$ However, this may be due to constants such as the A constant in linear IOL calculation formulae rather than errors in biometry. Calculation of the correlation coefficient (r) in our study, between the standard deviation and mean measurements, demonstrates no significant relationship of error with axial length or keratometry value. This suggests that a significant measurement error is just as likely to occur with a short or a long eye.

A modern reminder of the importance of accurate biometry for IOL power calculation is given in an account of the legal liability resulting from implantation of an IOL of

AXIAL LENGTH $=21.38 \mathrm{~mm}$
IENS THICHAESS
ATERIOR CHAMEER $=2.92 \mathrm{~mm}$

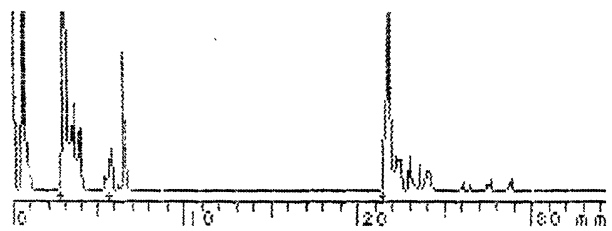

Fig. 1a. incorrect power. ${ }^{19}$ Expert testimony postulated inaccurate axial length and keratometry measurement and failure to measure both eyes as possible causes of the alleged breach. Two papers have further emphasised the role of biometry in accurate calculation of IOL power. ${ }^{17,18}$ In both papers axial length measurement was identified as being the major source of error and less accurate than keratometry, with short eyes being the most prone to error. ${ }^{17}$ Holladay and his colleagues ${ }^{18}$ gave instrumentation limitations as the reason for unexplained errors in IOL power calculation. They cited failure to take ultrasound velocity through cataractous lenses into account, as well as uncertainties over the uniformity of retinal thickness. They also proposed that the calibration of keratometers with steel balls might lead to errors when measuring an aspherical cornea. Many investigators have suggested sources of error in biometry. It is known that ultrasound travels more slowly through cataractous than normal adult lenses,${ }^{20}$ and this might lead to error in axial length estimation. Axial length measurement also differs with axis, and a five degree off-axis shift is suggested to cause a $0.3 \mathrm{~mm}$ variation in axial length. ${ }^{5}$ This may be a common source of error; two A-scan traces (Figure 1) may demonstrate prominent lens capsule and retinal reflections but give different axial lengths. When using an applanation type ultrasound probe, as in our study, corneal flattening may also lead to an apparent shortening of axial length. Hoffer ${ }^{21}$ has shown that there is no predictable symmetry between axial lengths or keratometry values of fellow eyes, and it is this that makes it important to perform biometry on both eyes
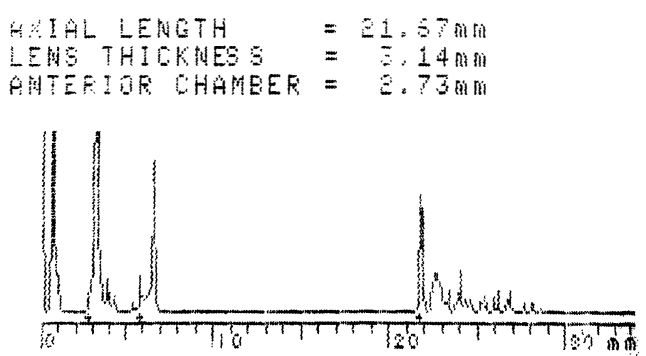

Fig. 1 b.

Fig. 1 Two A-scans of the same eye $(a, b)$ demonstrating good lens capsule and retinal reflections but different axial lengths. 
at the same sitting to improve accuracy of IOL power calculation. It is also recommended that an experienced operator should perform the measurements.

We conclude that biometry and keratometry are reproducible techniques. However, the difference between the initial reading and the mean of three or five readings shows a significant source of error in both techniques. This measurement error can lead to a larger error in determining IOL power for cataract surgery and neuro-retinal rim area for glaucoma. Clinically significant errors are just as likely to occur in small or large eyes. We recommend using the average of three readings to improve the accuracy of IOL power calculation, and reproducibility in measurement technique.

\section{References}

${ }^{1}$ Littmann $\mathrm{H}$ : The determination of the true size of objects in the background of the living eye. Klin Monatsbl Augenheilkd 1982, 180: 286-92.

${ }^{2}$ Caprioli $\mathbf{J}$ and Miller JM: Correlation of structure and function in glaucoma. Quantitative measurements of disc and field. Ophthalmology 1988, 95: 723.

${ }^{3}$ Jonas JB: Optic disc morphometry in chronic primary open angle glaucoma. Graefes Arch Clin Exp Ophthalmol 1988, 226: 531-8.

${ }^{4}$ Caprioli J, Ortiz-Colberg R, Miller JM, Tressler C: Measurements of peripapillary nerve fibre layer contour in glaucoma. Am J Ophthalmol 1989, 108: 404-13.

${ }^{5}$ Longstaff S: Factors affecting intraocular lens power calculation. Trans Ophthalmol Soc UK 1986, 105: 642-46.

${ }^{6}$ Hillman JS: The selection of intraocular lens power by calculation and by reference to the refraction-a clinical study. Trans Ophthalmol Soc UK 1982, 102: 495-7.

${ }^{7}$ Halliday BL: Calculation of intraocular lens power-results in practice. Trans Ophthalmol Soc $U K$ 1986, 105: 435-40.
${ }^{8}$ Thompson SM and Mohan-Roberts V: A comparison of postoperative results with and without intraocular lens power calculation. Br J Ophthalmol 1986, 70: 22-5.

${ }^{9}$ Hope-Ross $\mathbf{M}$ and Mooney D: Intraocular lens power calculation. Eye 1988, 2: 367-9.

${ }^{10}$ Singh $M$ and Dahalan A: Significance of intraocular lens power calculation. Br J Ophthamol 1987, 71: 850-3.

${ }^{11}$ Thompson SM and Mohan-Roberts V: Clinical indications for intraocular lens power calculation: A prospective randomised study. Eye 1989, 3: 696-703.

${ }^{12}$ Singh K, Sommer A, Jensen AD, Payne JW: Intraocular lens power calculations. Arch Ophthalmol 1987, 105: 1046-50.

${ }^{13}$ Hannush SB, Crawford SL, Waring GO, Gemmill MC, Lynn MJ, Nizham A: Reproducibility of normal corneal power measurements with a keratometer, photokerascope and video imaging system. Arch Ophthalmol 1990, 108: 539-44.

${ }^{14}$ Sanders DR and Kraff MC: A comparison of the Digital biometry ruler-300 and Echo-oculometer-3000: A report of 200 cases. Am Intraocular Implant Soc J 1982, 8: 365-9.

${ }^{15}$ Gregory PTS, Esbester RM, Boaze DL: Accuracy of routine intraocular lens power calculation in a district general hospital. Br J Ophthalmol 1989, 73: 57-60.

${ }^{16}$ Lindstrom RL, Lindstrom CW, Harris WS: Accuracy of lens implant power determination using A-scan. Contact Lens 1979, 5: 61-6.

${ }^{17}$ Richards SC, Olsen RJ, Richards WL: Factors associated with poor predictability by intraocular lens calculation formulae. Arch Ophthalmol 1985, 103: $515-8$.

${ }^{18}$ Holladay JT, Prager TC, Ruiz RS, Lewis JW, Rosenthal H: Improving the predictability of intraocular lens power calculations. Arch Ophthalmol 1986, 104: 539-41.

${ }^{19}$ Insler MS: Liability for intraocular lens calculations. Am J Ophthalmol 1990, 110: 578-9.

${ }^{20}$ Coleman DJ, Lizzi FL, Franzen LA, Abramson DH: A determination of the velocity of ultrasound in cataractous lenses. Bibl Ophthalmol 1975, 83: 246-51.

${ }^{21}$ Hoffer KJ: Biometry of 7500 cataractous eyes. Am J Ophthalmol 1980, 90: 360-8. 